\title{
A Morphometric Study on the Skull of the Turkeys (Meleagris gallopavo)
}

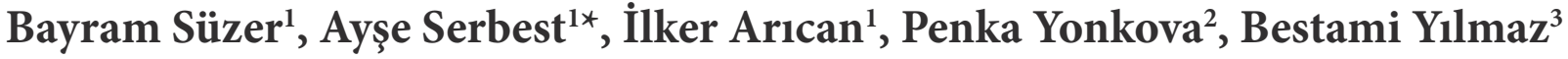 \\ ${ }^{1}$ Department of Anatomy, Faculty of Veterinary Medicine, Uludag University, Bursa, Turkey \\ ${ }^{2}$ Department of Veterinary Anatomy, Histology and Embryology, Faculty of Veterinary Medicine, \\ Trakia University, Stara Zagora, Bulgaria \\ ${ }^{3}$ Department of Anatomy, Faculty of Veterinary Medicine, Harran University, Sanliurfa, Turkey
}

Received 08.02.2018 Accepted 01.03.2018

\begin{abstract}
In this study, 80 turkey skulls ( 40 females and 40 males) were used. Turkeys slaughtered at the age of 128 days. The females had an average weight of $11.5 \mathrm{~kg}$ and the males had $19 \mathrm{~kg}$. We measured 14 features and determined 6 indices on the skulls of turkeys. Our study focused on morphometric differences and comparison of determined features of those skulls for males and female turkeys. Correlations between all features and indices of the skulls were examined for each male and female group, separately. All morphometric measurements were significantly higher in male group. All indices except skull index and foramen magnum index were significantly higher in female group. These measurements showed that males have bigger skulls. Cranial index, facial index, index 1 and index 2 showed that males have narrower and longer skulls while the females have smaller and wider. According to foramen magnum index, foramen magnum of turkeys is slightly vertical oval. Also, ratio of skull length and width is similar for both sexes. This study is the morphometric evaluation of the skull in turkeys. Therefore, this study will lead to further studies on turkeys and other bird species.
\end{abstract}

Keywords: Meleagris gallopavo, Morphometry, Skull anatomy, Turkey.

\section{Introduction}

The skeleton is important to zoologists and paleontologists for phylogenetic and taxonomic reasons. It is also important to veterinarians for economic reasons, since skeletal disorders cause financial loss to the poultry and turkey industry (King and McLelland, 1975). Birds possess one of the most highly specialized skulls among the living vertebrates (Bahadır, 2002; Feduccia, 1975). The avian skull is structurally and functionally composed of the rostrum, the orbits and the braincase (Morugán-Lobón and Buscalioni, 2006). The most distinctive feature of the avian skulls is that they have several shapes and variable dimensions (Zusi, 1993).
Various studies have been carried out on the avian skull morphology. Some of these studies have been performed on different avian species, such as penguins (Acosta, 2009; Acosta and Tambussi, 2006) skuas (Acosta et al., 2009) and tinamidae (Degrange and Picasso, 2010) and some of them have been fulfilled using geometric morphometric methods (Acosta, 2009; Acosta and Tambussi, 2006; Degrange and Picasso, 2010; Morugán-Lobón and Buscalioni, 2006). In another study, the characteristics of the neurocranial shape variations of birds have been examined by using the advanced graphical imaging method (Morugán-Lobón and Buscalioni, 2009).

Neurocranium is relatively small, compact and round-tapered in avian species. The length of neurocranium is about $26 \mathrm{~mm}$ in the medium-sized chickens, $41 \mathrm{~mm}$ in

*Corresponding author: Uludağ Üniversitesi, Veteriner Fakültesi, Anatomi Anabilim Dalı, 16059 Bursa, Türkiye

Tel: +902242941253 Fax: +902242941202 E-posta: aserbest@uludag.edu.tr 
goose; the width is $23 \mathrm{~mm}$ in chicken and $30 \mathrm{~mm}$ in goose (Schwarze and Schroder, 1979).

The morphometry of the skull have been examined in dogs (Onar and Gunes, 2003), cats (Kunzel et al., 2003), goats (Olopade and Onwuka, 2004; 2008; 2009a; 2009b), horses (Evans and McGreevy, 2006) and sheep (Parés et al., 2010). The geometric, morphometric analysis on avian anatomy is rare (Degrange and Picasso, 2010) and its use in morphological studies of birds is not common (Morugán-Lobón and Buscalioni, 2006). Therefore, the aim of the study is to evaluate the measurements of the skulls of turkeys.

\section{Materials and Methods}

In this study, 80 Hybrid Converter turkey skulls (40 females and 40 males) were used, which were fed with standard feed by a turkey breeding company and slaughtered for sale. These animals were slaughtered at the same day. The turkeys were 128 days old. The average weights of female and male turkeys were $11.5 \mathrm{~kg}$ and $19 \mathrm{~kg}$, respectively. The maceration was made according to the technique described by Tasbas and Tecirlioglu (1965) for the avian species.

The measurement points were determined to identify the characteristics of the anatomical structure of turkey skulls according to Gusselkoo et al. (2001), Hall et al. (2009), Onar (1999), Onar et al. (1997) and Singh et al. (2015). Specified measurement points were named according to Nomina Anatomica Avium (NAA) (Baumell et al., 1993). The measurement points defined on the skull are shown in Figure 1-4. Digital calliper was used to take the measurements.

\section{Descriptions of measurements:}

1. Skull length (SL): Length between prominentia cerebellaris and apex of rostrum maxillae.

2. Cranial length (CL): Length between prominentia cerebellaris and middle point of frontonasal suture.

3. Viscerocranial length (VL): Length between middle point of frontonasal suture and apex of rostrum maxillae.

4. Maximum width of neurocranium (MWN): Width between the bases of processus postorbitalis.

5. Beak width (BW): Width between caudal ends of processus maxillaris of premaxilla.

6. Zygomatic width (ZW): Width between projections of lateral frontonasal suture on arcus jugalis.

7. Skull height (SH): Height between the most prominent points of os frontale and lamina parasphenoidalis.

8. Basal length (BL): Length between caudal edge of condylus occipitalis and apex of rostrum maxillae.

9. Maximum width of the base of processus paroccipitalis (MWP): Width between lateral edges of processus paroccipitalis.

10. Height of the occipital area (HO): Height between middle of crista nuchalis transversus and middle of the ventral margin of foramen magnum.

11. Height of foramen magnum (HF): Height between middle of dorsal and ventral margins of foramen magnum. 12. Width of foramen magnum (WF): Maximum width of foramen magnum.

13. Height of condylus occipitalis (HC): Height between middle of dorsal and ventral margins of condylus occipitalis.

14. Width of condylus occipitalis (WC): Maximum width of condylus occipitalis.

Indices:

SKIND: Skull index $=($ Zygomatic width $\mathrm{x} 100) /$ Skull length

CRIND: Cranial index $=($ Maximum width of neurocranium $x$ 100)/Cranial length

FACIND: Facial index $=($ Zygomatic width $\mathrm{x} 100) /$ Viscerocranial length

IND1: Index 1= (Maximum width of neurocranium $\mathrm{x} 100)$ /Skull length

IND2: Index 2= (Maximum width of neurocranium $x$ 100) /Basal length

FORIND: (Foramen magnum index= Height of foramen magnum $\mathrm{x}$ 100) Width of foramen magnum

\section{Statistical analysis}

Statistical analyses were performed with statistical software SPSS (SPSS, Version 23.0; Chicago, IL). Data were tested for normality distribution and variance homogeneity assumptions. Data were stated as mean \pm standard error of 
the mean (SEM). Independent samples t-test was applied to the all parameters to examine the difference between groups. Pearson correlation test were used on SPSS to determine the interactions between each parameter for males and females, separately (Snedecor and Cochran, 1989).

\section{Results}

Correlation analysis of defined features were shown in Table 1 and comparison of the results between males and females were presented in Table 2.

All morphometric measurements were significantly higher in male group $(\mathrm{P}<0.05)$. All indices except SKIND and FORIND were significantly higher in female group $(\mathrm{P}<0.05)$. There was no significant difference between males and females in terms of SKIND and FORIND ( $\mathrm{P}>0.05)$.

The positive correlation among SKIND, ZW and FACIND was high for both males and females. Although males had no interactions among SKIND, IND1, IND2, SL and BL, the positive correlation among SKIND, IND1 and IND2 was medium and the negative correlation among SKIND, SL and BL was also medium in females. There was a high positive correlation among CRIND, MWN, IND1 and IND2 for both sexes. Also, medium positive correlation was observed between CRIND and VL in females. In males, the negative correlations among CRIND, SL, CL and $\mathrm{SH}$ were high but with $\mathrm{BL}$ was medium.

In females, CRIND and CL showed high negative correlation but with BW was medium as well. The positive correlation between FACIND and ZW was high and the negative correlation between FACIND and VL was medium for both sexes. But, females had medium to positive correlation between FACIND and CL. FORIND index showed high negative correlation with WF in both males and females. Although, positive correlation between FORIND and HF was medium for males, but it was high for females. Also, males had high positive correlation between FORIND and HO. While there was high positive correlation between IND1 and IND2, IND1 and IND2 had high positive correlation with MWN and also IND1 and IND2 showed high negative correlation with SL and BL in two sexes. In males, IND1 and IND2 had high negative correlations with VL and had medium negative correlation with CL, BW and SH.

In males, medium positive correlation was observed among HF, HO and WF; between WC and HC; SH and BL, CL, ZW and SL; BW and SL; respectively. Also, high positive correlation was determined between $\mathrm{VL}$ and $\mathrm{BL}$; CL and BL; SL and BL, VL and CL; respectively. In females, positive correlations among VL, SH and MWP; SL and VL;

\begin{tabular}{|c|c|c|c|c|c|c|c|c|c|c|c|c|c|c|c|c|c|c|c|c|}
\hline \multicolumn{21}{|c|}{ Females } \\
\hline & $\mathrm{SL}$ & $\mathrm{CL}$ & VL & MWN & BW & $\mathrm{ZW}$ & $\mathrm{SH}$ & $\mathrm{BL}$ & MWP & $\mathrm{HO}$ & $\mathrm{HF}$ & WF & $\mathrm{HC}$ & WC & SKIND & CRIND & $\begin{array}{l}\text { FAC } \\
\text { IND }\end{array}$ & IND1 & IND2 & $\begin{array}{l}\text { FOR } \\
\text { IND }\end{array}$ \\
\hline \multicolumn{21}{|l|}{ Males } \\
\hline SL & & .276 & $348^{*}$ & .065 & -135 & ,203 & .043 & $924^{*}$ & .275 &,- 194 &,- 189 &, 144 &,- 135 &, 066 & $-420^{*}$ &,- 158 & -019 &,$- 771^{* *}$ &,$- 709^{* *}$ &,- 257 \\
\hline $\mathrm{CL}$ & ,655" & & $-347^{*}$ &,- 001 &, $412^{* *}$ &, 144 &, 089 &, 213 &, 124 & .047 & -069 &, 036 &,- 188 &, 116 &,- 041 &,$- 740^{* *}$ & $338^{\circ}$ &,- 224 &,- 169 &,- 072 \\
\hline VL &, $737^{* *}$ & .282 & & 299 & $-473^{* *}$ &, 136 & $350^{*}$ &, 267 & $.396^{\circ}$ &, 043 &, 095 &, 011 &, 098 &, 046 & -079 & $.453^{* *}$ & $-468^{* *}$ &,- 095 &,- 061 &, 069 \\
\hline MWN &,- 059 &, 113 &,- 028 & & -069 & 266 & 013 &,- 084 & 051 & .123 &,- 136 &,- 127 &, 183 &, 106 & 211 &, $673^{* *}$ &, 053 &, $584^{* *}$ &, $601^{* *}$ &,- 030 \\
\hline BW & $493^{*}$ & .250 & $498^{*}$ & -039 & &, 017 & 006 &,- 172 & -0.015 & -066 &, 092 &,- 012 & -019 & .030 & .093 & $-353^{*}$ &, 296 & .069 &, 109 &, 091 \\
\hline $\mathrm{ZW}$ &, 171 & .023 & .155 & 066 & 094 & &, 074 &, 203 &, 125 & .159 &,- 120 &, 005 &,- 131 &, 163 &, $803^{* *}$ & 075 &, $811^{* *}$ & ,006 &,- 016 &,- 094 \\
\hline $\mathrm{SH}$ & $461^{*}$ & $.486^{*}$ & 291 &,- 176 & .225 & $.315^{\circ}$ & &,- 043 & .289 &, 161 &, 231 &, 075 & .036 & -.043 &, 046 &,- 060 &,- 141 &,- 033 &, 027 &, 127 \\
\hline $\mathrm{BL}$ & ,931" &, $506^{* *}$ & ,697"* & -053 &, $509^{*}$ &, 154 & $403^{* *}$ & & .225 & -241 &,- 093 &, 203 &,- 116 & .046 & $-379^{*}$ &,- 212 &, 028 & $-806^{* *}$ &,$- 846^{* *}$ &,- 218 \\
\hline MWP & .238 &, 184 & 267 & 087 & $341^{\circ}$ &, 282 & 021 & ,195 & & .007 &, 110 &, 217 & -131 &, 232 &,- 052 & -054 & -113 &,- 191 &,- 154 &,- 071 \\
\hline HO &,- 109 & -206 &,- 039 & .051 &, 005 & ,049 &,- 091 & 009 &, 112 & & 309 &, 111 &, 158 &,- 097 & .263 &, 044 & ,113 & .231 & .250 & ,173 \\
\hline $\mathrm{HF}$ & .017 & -.061 &,- 025 &, 158 & -204 &, 157 & -.226 &, 100 &, 228 & $345^{*}$ & &, 207 &, 209 & -008 &,- 001 &,- 047 & -167 &, 065 &, 005 & ,684 \\
\hline WF & .091 &, 130 &, 188 & -008 & -113 & 210 & $=005$ & 071 & .276 & -282 & $329^{*}$ & &, 023 &, 104 &,- 084 & -102 &, 008 &,- 195 &,- 226 &,$- 570^{* *}$ \\
\hline $\mathrm{HC}$ &,- 061 & $-0,054$ & .048 & 007 & -135 &,- 271 & -163 &,- 024 & -.080 &,- 125 & -082 & ,102 & &, 302 & -043 & 260 & -184 & .224 & 190 &, 161 \\
\hline wC &, 059 & .250 &,- 063 &,- 118 & .051 &,- 198 &,- 102 &, 066 & .082 &,- 154 &, 054 &, 044 & $464^{*}$ & &, 102 &,- 010 & .119 & ,006 & 012 & -091 \\
\hline $\begin{array}{l}\text { SK } \\
\text { IND }\end{array}$ &,- 208 &,- 221 &,- 127 & 091 & $-0,095$ &, $928^{* *}$ &, 140 & -200 &, 191 &, 092 &, 150 &, 170 &,- 248 &,- 221 & &, 174 &, $759^{* *}$ & $478^{* *}$ & $.422^{*}$ &, 066 \\
\hline $\begin{array}{l}\text { CR } \\
\text { IND }\end{array}$ &,$- 585^{+*}$ &,$- 764^{+*}$ &,- 247 &, $554^{+*}$ &,- 231 &, 019 &,$- 522^{+*}$ & $-458^{* *}$ &,- 092 &, 206 &, 154 &,- 116 &, 048 & -290 & .240 & &,- 209 &, $557^{* *}$ &, $528^{*+}$ &, 021 \\
\hline $\begin{array}{l}\text { FAC } \\
\text { IND }\end{array}$ &,- 211 & -123 & $-356^{\circ}$ & .081 & -162 &, $867^{* *}$ &, 156 &,- 210 &, 140 &, 070 & ,154 &, 097 & -287 &,- 166 & ,943** & 148 & & .053 &, 013 &,- 135 \\
\hline IND1 &,$- 764^{+*}$ & $-405^{* *}$ &,$- 551^{*}$ & ,689"* &,$- 381^{*}$ & -0.079 &,$- 448^{* *}$ &,$- 713^{* *}$ &,- 115 & .111 & .084 &,- 079 &, 045 &,- 126 & .212 &, $785^{* *}$ & 207 & &, $962^{* *}$ &, 186 \\
\hline IND2 &,$- 734^{* *}$ & -311 &,$- 540^{* \prime}$ & $=657^{\prime *}$ & $-405^{*}$ & -070 & $-409^{*}$ & -,787" & -.091 & .023 & .012 &,- 071 & .018 & -131 &, 211 & ,687" &, 212 &, $960^{* *}$ & &, 158 \\
\hline $\begin{array}{l}\text { FOR } \\
\text { IND }\end{array}$ &,- 078 & -169 &,- 201 &, 144 & -064 & -.063 & -186 &, 008 & -.067 &, $524^{*}$ & $494^{*}$ & - $657^{* *}$ & -153 &, 007 &,- 028 & 237 &, 043 &, 152 &, 086 & \\
\hline
\end{tabular}

Table 1. Correlation analysis of the defined features in turkey skulls. Lower left side shows males, upper right side shows females.

${ }^{*}$. Correlation is significant at the 0.05 level. ${ }^{* *}$. Correlation is significant at the 0.01 level. Bold parameters indicate high correlations 


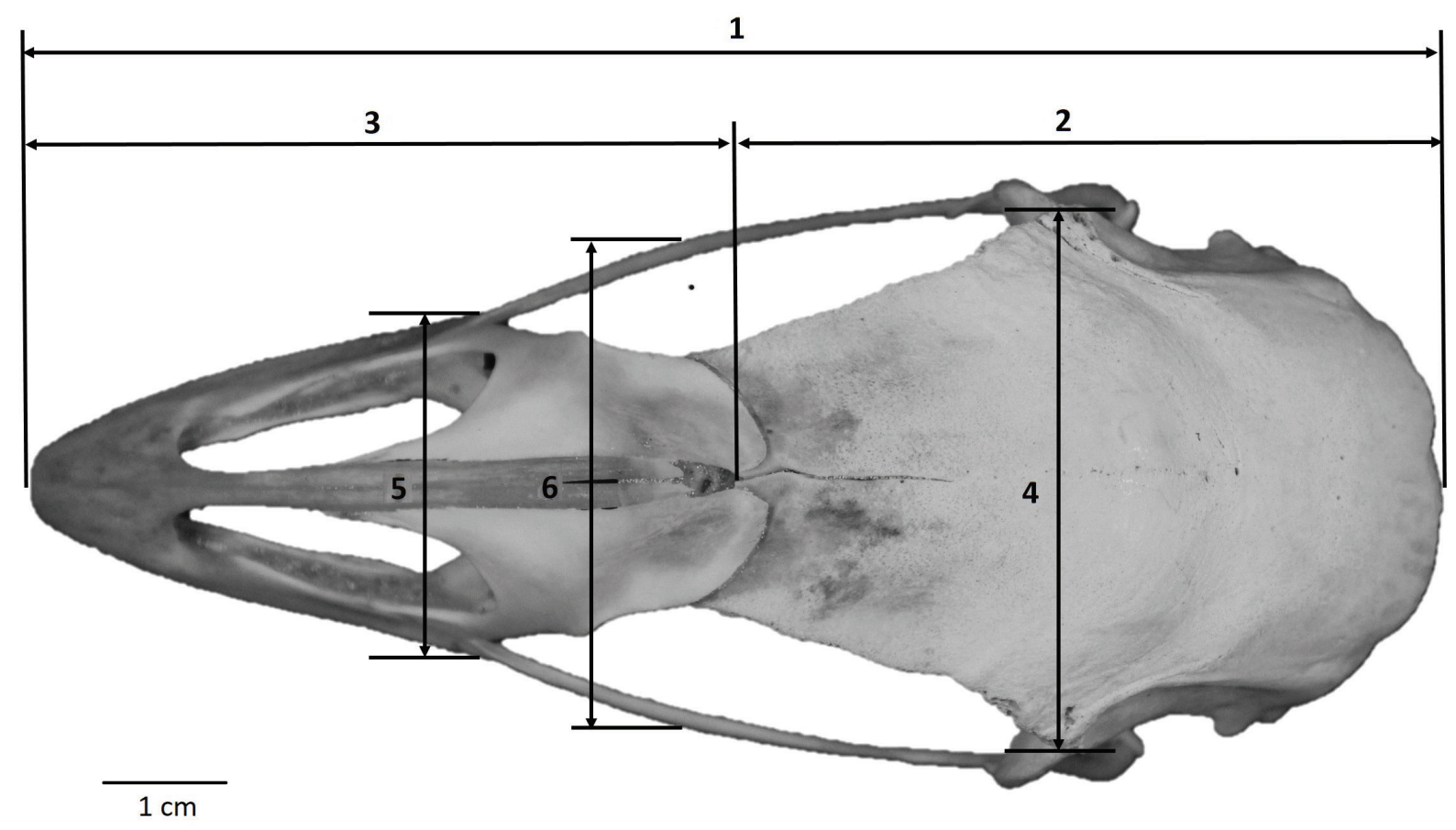

Figure 1. Reference points of cranium (dorsal view) $\ddagger$

\$1. Skull length (SL), 2. Cranial length (CL), 3. Viscerocranial length (VL), 4. Maximum width of neurocranium (MWN), 5. Beak width (BW), 6. Zygomatic width (ZW).

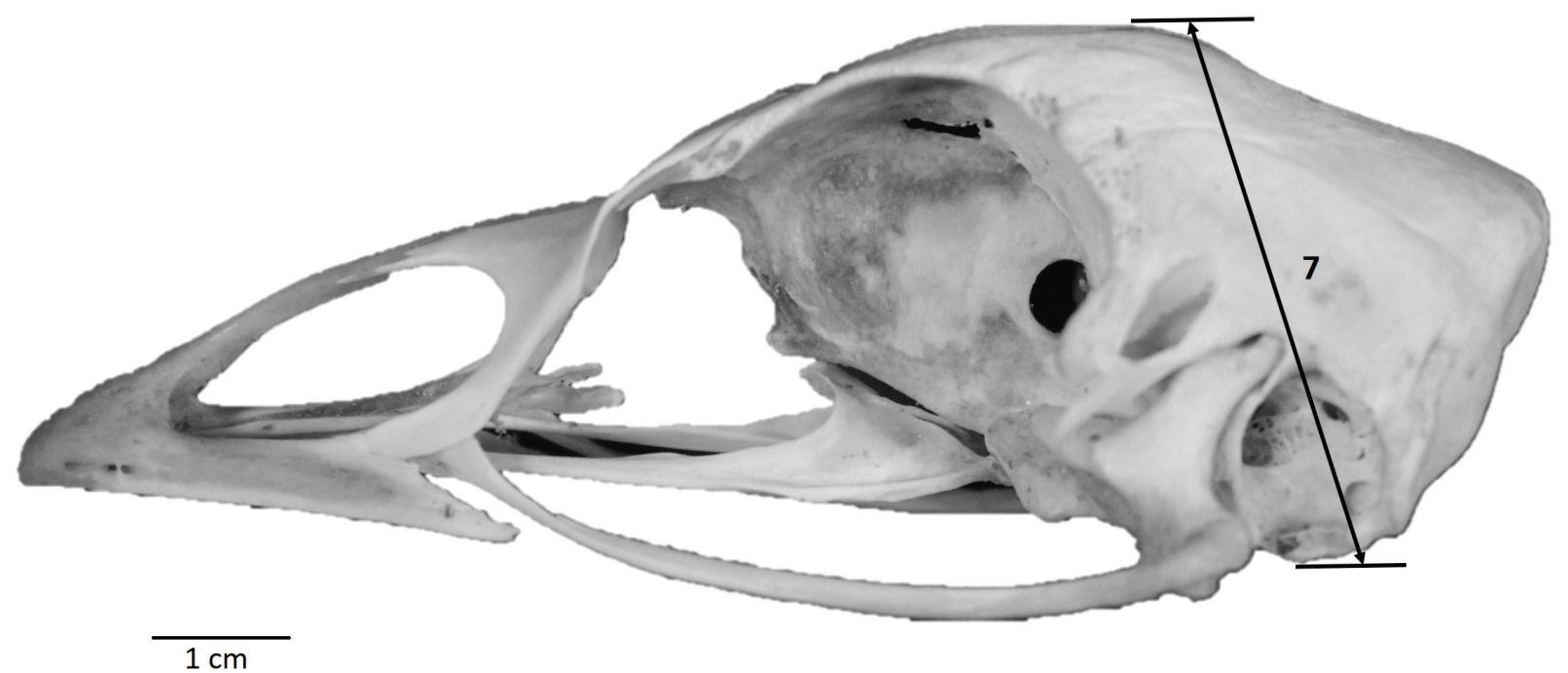

Figure 2. Reference points of cranium (lateral view) $\ddagger$

‡. Skull height (SH). 


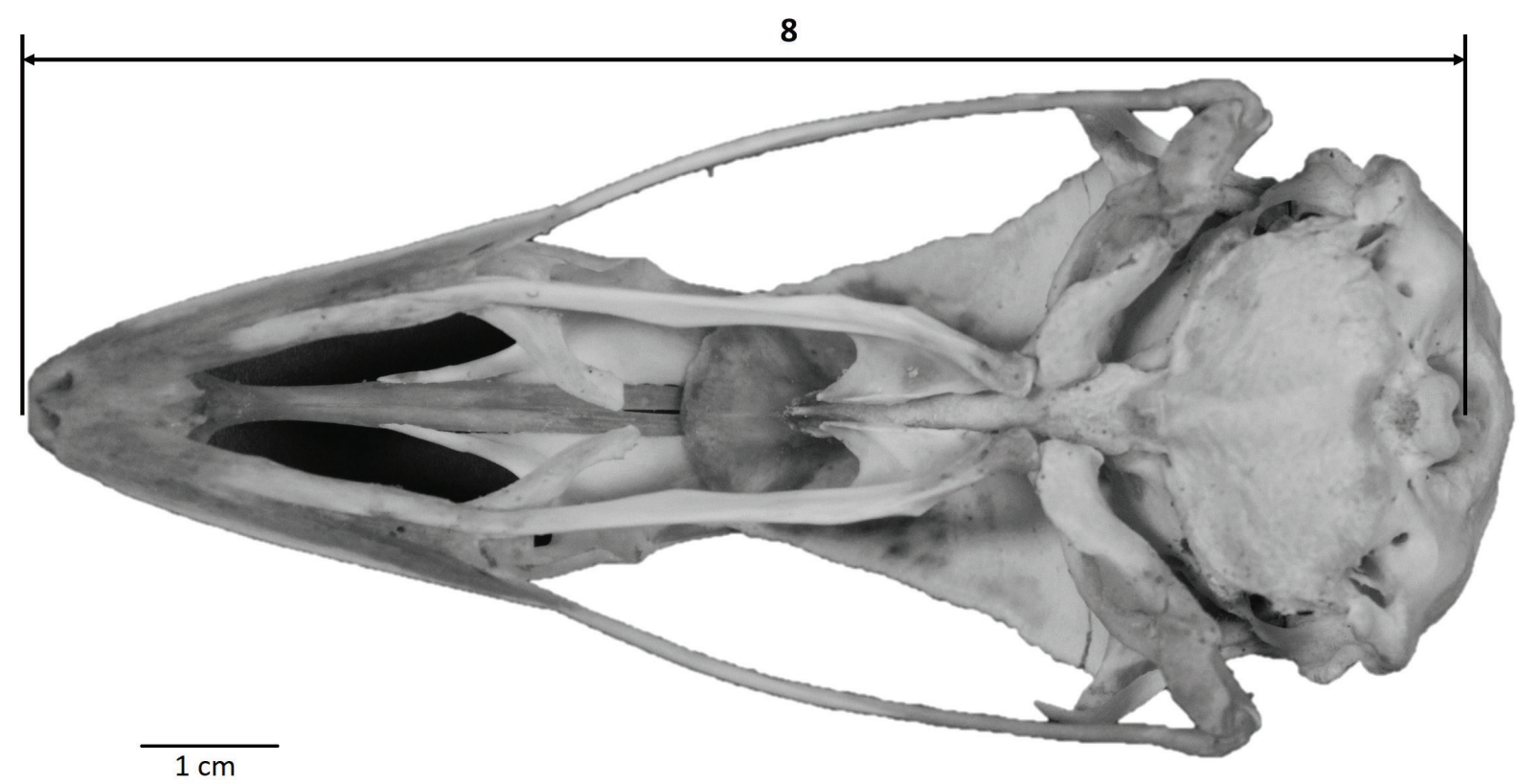

Figure 3. Reference points of cranium (ventral view) $\ddagger$ $\ddagger 8$. Basal length (BL).

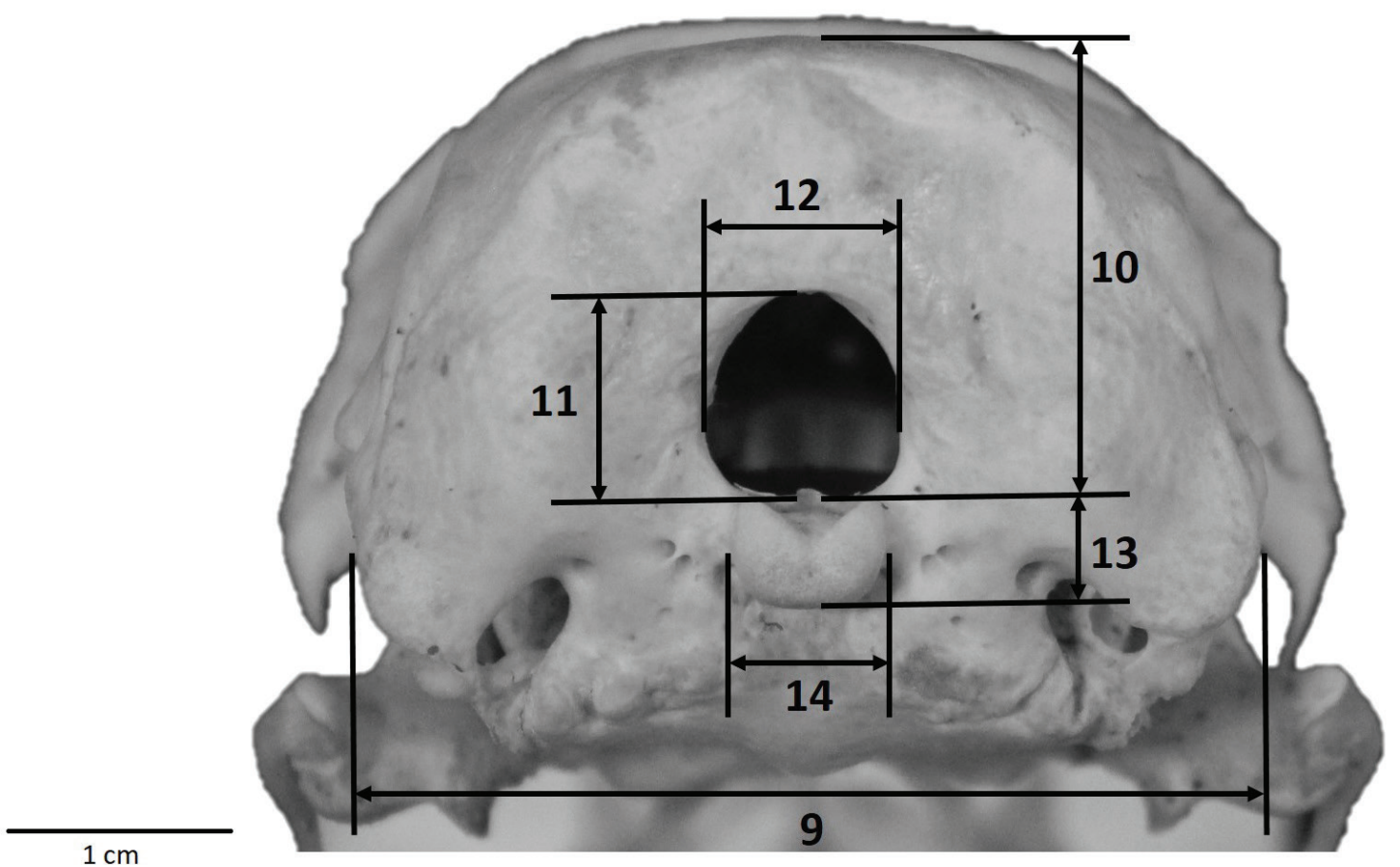

Figure 4. Reference points of cranium (caudal view) $\neq$

\$. Maximum width of the base of processus paroccipitalis (MWP), 10. Height of the occipital area (HO), 11. Height of foramen magnum (HF), 12. Width of foramen magnum (WF), 13. Height of condylus occipitalis (HC), 14. Width of condylus occipitalis (WC). 


\begin{tabular}{|c|c|c|c|c|c|c|c|c|c|c|c|c|c|c|c|c|c|c|c|c|c|}
\hline & & SL & CL & VL & MWN & BW & ZW & SH & BL & MWP & HO & HF & WF & $\mathrm{HC}$ & WC & $\begin{array}{c}\text { SK } \\
\text { IND }\end{array}$ & $\begin{array}{r}\text { CR } \\
\text { IND } \\
\end{array}$ & $\begin{array}{l}\text { FAC } \\
\text { IND }\end{array}$ & IND1 & IND2 & $\begin{array}{l}\text { FOR } \\
\text { IND }\end{array}$ \\
\hline \multirow{2}{*}{ 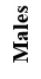 } & Mean & $116,134^{*}$ & $56,6898^{*}$ & $65,1462^{*}$ & $42,7113^{*}$ & $29,084^{*}$ & $43,0125 *$ & $42,4585^{*}$ & $108,435^{*}$ & $38,7393^{*}$ & $18,7663^{*}$ & $9,4043^{*}$ & $8,7347^{*}$ & $3,9210^{*}$ & $6,6930^{*}$ & 37,0467 & $75,3866^{*}$ & $66,0693^{*}$ & $36,7963^{*}$ & $39,4127^{*}$ & 107,9266 \\
\hline & SEM $^{\dagger}$ & 0,41175 & 0,22984 & 0,32118 & 0,13421 & 0,19469 & 0,39988 & 0,23716 & 0,41555 & 0,13796 & 0,12200 & 0,07680 & 0,08177 & 0,03913 & 0,04869 & 0,34909 & 0,36826 & 0,65425 & 0,17938 & 0,20306 & 1,09065 \\
\hline \multirow{2}{*}{ 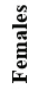 } & Mean & $96,5300^{*}$ & $51,1737 *$ & $53,3988^{*}$ & $39,4150^{*}$ & $23,484^{*}$ & $36,2862^{*}$ & $36,3833^{*}$ & $88,3740^{*}$ & $34,1408^{*}$ & $16,9370^{*}$ & $8,3258^{*}$ & $7,5410^{*}$ & $3,5595^{*}$ & $5,9695^{*}$ & 37,6155 & $77,0741^{*}$ & $68,0050^{*}$ & $40,8688^{*}$ & $44,6606^{*}$ & 110,6233 \\
\hline & SEM $^{\dagger}$ & 0,47875 & 0,21449 & 0,26389 & 0,15069 & 0,23154 & 0,27016 & 0,18793 & 0,50826 & 0,11911 & 0,10950 & 0,07627 & 0,06085 & 0,03373 & 0,05413 & 0,30558 & 0,43183 & 0,57243 & 0,24766 & 0,31840 & 1,20870 \\
\hline \multirow{2}{*}{$\stackrel{\vec{a}}{\underline{a}}$} & $t$ & 31,047 & 17,546 & 28,261 & 16,335 & 18,512 & 13,938 & 20,077 & 30,557 & 25,229 & 11,159 & 9,964 & 11,711 & 6,997 & 9,937 & $-1,226$ & $-2,973$ & $-2,227$ & $-13,318$ & $-13,897$ & $-1,656$ \\
\hline & $\mathbf{P}$ & 000 & 000 & 000 & .000 & ,000 & 000 & .000 & .000 & .000 & 000 &, 000 & .000 & 000 & 000 & .224 & .004 & 029 & .000 & .000 & 102 \\
\hline
\end{tabular}

Table 2. Comparison of the defined features between male and female turkey skulls.

*. Means with different superscripts in the same row differ at $\mathrm{P}<0.05$.

$\dagger$. Standart Error of Mean

$\mathrm{SL}=$ Skull length, $\mathrm{CL}=$ Cranial length, $\mathrm{VL}=$ Viscerocranial length, $\mathrm{MWN}=$ Maximum width of neurocranium, BW=Beak width, $\mathrm{ZW}=\mathrm{Zygomatic}$ width, $\mathrm{SH}=\mathrm{Skull}$ height, $\mathrm{BL}=\mathrm{Basal}$ length, $\mathrm{MWP}=\mathrm{Maximum}$ width of the base of processus paroccipitalis, $\mathrm{HO}=\mathrm{Height}$ of the occipital area, $\mathrm{HF}=\mathrm{Height}$ of foramen magnum, $\mathrm{WF}=$ Width of foramen magnum, $\mathrm{HC}=$ Height of condylus occipitalis, WC=Width of condylus occipitalis, SKIND=Skull Index, CRIND=Cranial Index, FACIND=Facial Index, IND1=Index 1, IND2= Index 2, FORIND=Foramen Index.

CL and BW; CL and VL were medium. There was medium positive correlation between VL and BW in males. In contrast, the correlation between VL and BW was negative in females.

\section{Discussion and Conclusion}

In poultry species, neurocranium is relatively small, compact and round-tapered as described by Schwarze and Schröder (1979). Therefore, it is more difficult to determine reference points on the skulls of poultry species than mammals. There is not much information in the literatures about the measurements of skulls of poultry species in general. Therefore, we have not been able to compare the data obtained from the skull of turkeys.

Mc Lelland (1990) has reported that foramen magnum was in triangular shape in chickens. Nickel et al. (1977) also reported the position of foramen magnum was horizontally in pigeons and nuchal but vertically in duck and goose. Cakir (2001) pointed that foramen magnum placed oblique-caudoventral in bald ibis. Also, Ilgun et al. (2016) reported that the position of foramen magnum was vertical and nuchal in guinea fowl and turkeys. According to FORIND, the present study suggests foramen magnum of turkeys was also slightly vertical oval shaped. There is no significant difference in SKIND between males and females. This shows that the growth rate in the transverse and longitudinal directions of the skull is equal in males and females, separately. Therefore, the ratio of skull length and width is similar for both sexes.

Although all morphometric measurements were significantly higher in males, all indices except SKIND and FO-
RIND show that female skulls are widened width-wise. Indices show that males have narrower and longer skulls while the females have smaller and wider. Also, higher values of MWN, CL and SH in males support that the males have larger skulls and this might be the result of the larger brain as suggested by Moller (2009) and Singh et al. (2015). Male turkeys have larger skulls and this provides more attaching surfaces for muscles. Therefore, males have greater bite force compared to females and this feature provides males better feed grasping ability (Vermaijen et al., 2002). Also, larger beak width in male turkeys allows comfort to repositioning of large feeds in beak and it provides large gape for catching feed and sending it to pharynx (Gusselkoo and Bout, 2005).

The reference points and indices which can be used in avian morphometric studies are combined in this study. We expect that this study will help the researches who wish to study on morphometry of the skull of turkeys and other avian species.

\section{References}

Acosta Hospitaleche C. Variation in the cranial morphometry of the Magellanic Penguin (Spheniscus magellanicus). Ornitol Neotrop, 20: 19-26, 2009.

Acosta Hospitaleche C, Tambussi C. Skull morphometry of Pygoscelis (Sphenisciformes): inter- and intraspecific variations. Polar Biol, 29: 728-734, 2006.

Acosta Hospitaleche C, Montalti D, Marti LJ. Skeletal morphoanatomy of the brown skua Stercorarius antarticus lon- 
nbergi and the south polar skua Stercorarius maccormicki. Polar Biol, 32: 759-774, 2009.

Bahadır A. Osteologia. In. Dursun N (Ed.), Evcil Kuşların Anatomisi. 1. Baskı, Medisan Yayınevi, Ankara, pp. 4-28, 2002.

Baumell JJ, Witmer LM. Osteologia. In. Baumel JJ, Breazile JE, Evans HW, Van den Berge JC (Eds.), Handbook of Avian Anatomy: Nomina Anatomica Avium. 2nd Edition, Publications of the Nuttal Ornithological Club, Cambridge, Massachusetts, pp. 45-132, 1993.

Cakir A. Kelaynak kuşunda (Geronticus eremita) neurocranium kemikleri. Türk Vet Hek Bir Der, 72: 35-38, 2001.

Degrange FJ, Picasso MBJ. Geometric morphometrics of the skull Tinamidae (Aves, Palaeognathae). J Zool, 113: 334-338, 2010.

Evans KE, McGreevy PD. Conformation of the equine skull: a morphometric study. Anat Histol Embryol, 35: 221-227, 2006.

Feduccia A. Aves Osteology. In. Getty R (Ed.), Sisson and Grossman's The Anatomy of the Domestic Animals. Vol. 2, 5th Edition, W. B. Saunders Company, Philadelphia, pp. 1790-1801, 1975.

Gusselkoo WS, Bout RG. Cranial kinesis in palaeogna-thous birds. J Exp Biol, 208: 3409-3419, 2005

Gussekloo SWS, Vosselman MG, Bout RG. Threedimen-sional kinematics of skeletal elements in avian prokinetic and rhynchokinetic skulls determined by roentgen stereo-photogrammetry. J Exp Biol, 204: 1735-1744, 2001.

Hall MI, Iwaniuk AN, Gutierrez-Ibanez C. Optic foramen morphology and activity pattern in birds. Anat Rec, 292: 1827-1845, 2009.

Ilgun R, Akbulut Y, Kuru N. Beç tavuğu (numida meleagridis) ve hindi (meleagridis gallapova) neurocranium'u üzerinde karşılaştırmalı makro-anatomik ve morfometrik incelemeler. FÜ Sağ Bil Vet Derg, 30: 29-32, 2016.
King AS, McLelland J. Outlines of Avian Anatomy. First published, Bailliére Tindall, London, 1975.

Kunzel W, Breit S, Oppel M. Morphometric investigations of breed specific features in feline skulls and considerations on their functional implications. Anat Histol Embryol, 32: 218-223, 2003.

McLelland J. A color atlas of avian anatomy. Wolfe Publishing Ltd, London, 1990.

Moller AP. Brain size, head size and behaviour of a passerine bird. J Evol Biol 23: 625-635, 2009.

Morugán-Lobón J, Buscalioni AD. Avian skull morphological evolution: exploring exo- and endocranial covariation with two block partial least squares. J Zool, 109: 217-230, 2006.

Morugán-Lobón J, Buscalioni AD. New insight on the anatomy and architecture of the avian neurocranium. Anat Rec, 292: 364-370, 2009.

Nickel R, Schummer A, Seiferle E. Anatomy of the Domestic Birds. Verlag Paul Parey, Berlin, 1977.

Olopade JO, Onwuka SK. Morphometric studies of the craniofacial region of the West African Dwarf Goat in Nigeria. Int J Morphol, 22: 145-148, 2004.

Olopade JO, Onwuka SK. A craniometric analysis of the skull of the red Sokoto (Maradi) goat (Capra hircus). Eur J Anat, 12: 57-62, 2008.

Olopade JO, Onwuka SK. Morphometric analysis of the skull of the Sahel goat breed: basic and clinical anatomy. Ital J Anat Embryol, 114: 167-178, 2009a.

Olopade JO, Onwuka SK. A review of the craniofacial and neurometric anatomy of the goat. Trop Vet, 27: 1-19, 2009b.

Onar V. A Morphometric study on the skull of the German Shepherd dog (Alsatian). Anat Histol Embryol, 28: 253-256, 1999.

Onar V, Günes H. On the variability of skull shape in Ger99 man Shepherd (Alsatian) puppies. Anat Rec, 272A: 460- 
466, 2003.

Onar V, Mutuş R, Kahvecioğlu KO. Morphometric analysis of the foramen magnum in German Shepherd dogs (Alsatians). Ann Anat, 179: 563-568, 1997.

Parés, IC, Kamal S, Jordana J. On biometrical aspects of the cephalic anatomy of Xisqueta Sheep (Catalunya; Spain). Int J Morphol, 28: 347-351, 2010.

Schwarze E, Schröder L. Kompendium der Geflügelanatomy. 3. Auflage, Gustav Fisher, Verlag, Stuttgart, 1979.

Singh NS, Bamon I, Dixit AS. Structural variations and their adaptive significances in the bones of some migratory and resident birds. J Basic Appl Zool, 70: 33-40, 2015.

Snedecor GW, Cochran WG. Statistical Methods. 8th Edition, Iowa State University Press, Iowa, 1989.

Tasbas M, Tecirlioglu S. Maserasyon tekniği üzerinde araştırmalar. Ankara Üniv Vet Fak Derg, 4: 324-330, 1965.

Vermaijen D, Van Damme R, Herrel A. Relationships between head size, bite force, prey handling efficiency and diet in two sympatric lacertid lizards. Funct Ecol, 16: 842$850,2002$.

Zusi RL. Patterns of diversity in the avian skull. In. Hanken J, Hall B (Eds.), The Skull. Patterns of structural and systematic diversity. Vol. 2, The University of Chicago Press, Chicago, pp. 391-437, 1993. 